\title{
In Memoriam: John Allan Hobson (1933-2021)
}

\author{
Edward F. Pace-Schott ${ }^{1} \cdot$ Robert Stickgold $^{2}$
}

Published online: 11 August 2021

(c) The Author(s), under exclusive licence to Springer Nature Singapore Pte Ltd. 2021

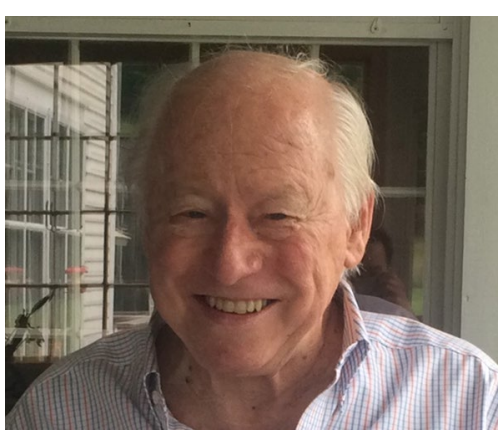

Preeminent neuroscientist and pioneer in sleep and dream research John Allan Hobson passed away on July 7, 2021 at his home in East Burke, Vermont. For over 5 decades, Allan was a friend, colleague, and mentor to a multitude of sleep and dream researchers and many outstanding careers emerged from his Laboratory of Neurophysiology at the Massachusetts Mental Health Center. Allan was born in 1933, grew up in West Hartford, CT, and attended the Loomis School (class of 1951), the Sutton Valence School in England, and Wesleyan University (class of 1955). He received his MD from Harvard Medical School and interned for 2 years at Bellevue Hospital in New York City. Afterward, while an officer in the Public Health Service of the National Institutes of Health in Washington DC, Allan met the pioneering experimental sleep neurophysiologist Michel Jouvet with whom he then completed a 2-year fellowship

Edward F. Pace-Schott

epace-schott@mgh.harvard.edu

Robert Stickgold

rstickgold@hms.harvard.edu

1 Sleep and Anxiety Disorders Laboratory, Department of Psychiatry, Massachusetts General Hospital, Harvard Medical School, CNY 149 13th Street Room 2605, Charlestown, MA 02129, USA

2 Harvard Medical School, Beth Israel Deaconess Medical Center, Boston, MA 02139, USA at the University of Lyon, France. When Allan returned, he founded the Laboratory of Neurophysiology at Massachusetts Mental Health Center in Harvard's Longwood Medical Area, a laboratory that he directed for nearly 5 decades and where he became Professor of Psychiatry at Harvard Medical School. Many important discoveries and theories emerged from this laboratory, notably, in collaboration with Dr. Robert McCarley, the seminal Reciprocal Interaction model of REM/NREM control and the first biologically based theory of dreaming, the Activation-Synthesis hypothesis. Allan continually evolved this dream theory over time to become the equally influential AIM model and, eventually, a theory of dreams as proto-consciousness that presaged emerging views on the predictive functions of the brain. Allan received many scientific honors including the 1998 Distinguished Scientist Award from the Sleep Research Society, an organization in which he was among the first members. Allan was also a clinician for most of his career, seeing patients, mentoring psychiatry residents, and consulting with agencies such as the Massachusetts Rehabilitation Commission. As a teacher, he conducted innumerable invited lectures and seminars as well as courses and seminars at Harvard University including an immensely popular, open enrollment course on sleep and dreaming at Harvard Extension School. In his academic career, Allan published over 20 books and hundreds of scientific articles, both activities he continued well into his eighties. His writings served not only his scientific colleagues and students but provided the general readership with exciting deep dives into the workings of the brain in sleep and dreaming. His collaborations were worldwide and he worked closely with scientists in the Americas, Europe, and Asia alike. His transcontinental scientific and social life was expanded with his marriage to Dr. Rosalia Silvestri, herself a prominent neuroscientist and clinical neurologist from Messina, Sicily, where he, Rosalia, their twins, and his step-children lived a good part of the year. From Sicily, Allan further nurtured his many collaborations and friendships with European colleagues and mentees. An exuberant host, Allan held frequent social gatherings in his homes in Brookline and Vermont attended 
by friends, colleagues, students, and visitors from all over the globe. Especially, memorable were his garden parties in Brookline often accompanied by live music provided by his friends, holiday and dance parties in his home often with live Dixieland music or impromptu talent shows, and overnight gatherings at his farm in West Burke Vermont where hikes in the gorgeous surrounding mountains were often the order of the day. Allan will be remembered as an immensely influential scientist whose ideas and writings will continue to influence and inspire neuroscientists, psychologists, sleep physicians, and all their students for years to come. Allan is survived by his wife, Dr. Rosalia Silvestri, son Ian, son and daughter-in-law Christopher Hobson and Mary Todd Goodspeed, sons Andrew and Matthew Hobson, daughter and son-in-law Julia and Mark Haggerty, brother and sister-in-law Bruce and Lynda Hobson, stepchildren Raffele, Elena, Giugi and Enzo Tanzariello and Luca and Caterina Di Perri, and grandchildren Henry and Chance Hobson and Lucy and Jude Haggerty.

Acknowledgements Photo credit: https://commons.wikimedia.org/ wiki/File:Allan_Hobson_in_Vermont_(July_2016).jpg.

Publisher's Note Springer Nature remains neutral with regard to jurisdictional claims in published maps and institutional affiliations. 